\title{
Potentially inappropriate medication use among hypertensive older African-American adults
}

\author{
Mohsen Bazargan ${ }^{1,2^{*}}$, James L Smith ${ }^{1}$ and Ebony O King ${ }^{1,2}$
}

\begin{abstract}
Background: Inappropriate use of medications, particularly among minority older adults with co-morbidity, remains a major public health concern. The American Geriatrics Society (AGS) reports that Potentially Inappropriate Medication (PIM) continues to be prescribed for older adults, despite evidence of poor outcomes. The main objective of this study was to examine the prevalence of PIM use among underserved non-institutionalized hypertensive older AfricanAmerican adults. Furthermore, this study examines potential correlations between PIM use and the number and type of chronic conditions.

Methods: This cross-sectional study is comprised of a convenience sample of 193 hypertensive non-institutionalized African-American adults, aged 65 years and older recruited from several senior housing units located in underserved areas of South Los Angeles. The updated 2015 AGS Beers Criteria was used to identify participants using PIMs.

Results: Almost one out of two participants had inappropriate medication use. While the average number of PIMs taken was 0.87 drugs, the range was from one to seven medications. Almost $23 \%$ of PIMs were due to drugs with potential drug-drug interactions. The most common PIM was the use of proton pump inhibitors (PPI) and Central Nervous System (CNS) active agents. Nearly 56\% of PIMs potentially increased the risk of falls and fall-associated bone fractures. The use of PIMs was significantly higher among participants who reported a higher number of chronic conditions. Nearly $70 \%$ of participants with PIM use reported suffering from chronic pain.

Conclusions: The major reason for high levels of polypharmacy, PIMs, and drug interactions is that patients suffer from multiple chronic conditions. But it may not be possible or necessary to treat all chronic conditions. Therefore, the goals of care should be explicitly reviewed with the patient in order to determine which of the many chronic conditions has the greatest impact on the life goals and/or functional priorities of the patient. Those drugs that have a limited impact on the patient's functional priorities and that may cause harmful drug-drug interactions can be reduced or eliminated, while the remaining medications can focus on the most important functional priorities of the patient.
\end{abstract}

Keywords: Potentially inappropriate medication (PIM), Minority, Older adults, Pain, Falls

\section{Background}

Older African-American adults have a high prevalence of many of the most potent cardiovascular disease risk factors, particularly hypertension (HTN) and diabetes mellitus [1]. The combination of HTN and diabetes is lethal and is associated with elevated all-cause and cardiovascular disease mortality among older adults $[2,3]$. In

\footnotetext{
* Correspondence: mobazarg@cdrewu.edu

'Charles R. Drew University of Medicine and Science, 1731 East 120th Street, Los Angeles, CA 90005, USA

${ }^{2}$ University of California, Los Angeles, USA
}

2015, more than $71 \%$ of older African American Medicare fee-for-service beneficiaries had at least two chronic conditions and $43 \%$ suffered from at least four conditions [4]. National data show that $39.8 \%, 45.6 \%$, and 64.4\% of older African-American Medicare adult beneficiaries have diabetes, hyperlipidemia, and HTN, respectively [5]. Effective treatment of these conditions often requires the prescribing of multiple medications. Within the last decade, prescription medication $(\mathrm{Rx})$ use has increased dramatically among older adults, i.e., the median number of $\mathrm{Rx}$ used doubled from 2 to 4 , and those

(c) The Author(s). 2018 Open Access This article is distributed under the terms of the Creative Commons Attribution 4.0 International License (http://creativecommons.org/licenses/by/4.0/), which permits unrestricted use, distribution, and 
taking more than 5 medications tripled from 13 to $39 \%$ [6]. This increase in medication use among older adults was driven, in part, by higher use of antidiabetics, anti-hypertensives, and statins [6]. The use of these medications has led to substantial improvements in Low-Density Lipoprotein Cholesterol, blood pressure and glycemic control. Despite these favorable outcomes, suboptimal use of medications among ethnic/racial population limits maximal health benefits [7-9]. Three major medication-related challenges that lead to suboptimal use of medications are: 1) nonadherence to prescribed drug regimens $[10-16], 2)$ excessive and unnecessary use of medication $[17,18]$, and 3) inappropriate use of medications [19].

The American Geriatrics Society reports that Potentially Inappropriate Medication (PIM) continues to be prescribed for older adults, despite evidence of poor outcomes from the use of PIMs in this segment of our population [20]. Several studies documented that PIM use has been associated with an increased risk of falls and hip fractures [21]. A recent systematic review documented that PIM use was associated with a 1.6-fold increased mortality in older adults [22]. Another recent meta-analysis of PIM use in community-dwelling older American adults found the median rate of PIM to be $19.6 \%$ with a range of 4.5 to $33.3 \%$ [23].

Prevalence estimates for PIMs represent an important healthcare quality metric [24]. Specifically, given the high rate of PIM use among underserved older AfricanAmerican adults, there is a need for ongoing monitoring of inappropriate medication use among this segment of our population. Additionally, it is important to continue investigating the extent and consequences of PIM use among those older African-American adults with medical conditions, such as cardiovascular disease, that place them at risk for poorer clinical outcomes. A recent study that examined PIM use among a large sample $(n=16,588)$ of non-institutionalized older adults (age $\geq 65$ ) from the 2006-2010 Medical Expenditure Panel Survey documented strong associations between PIM use and cardiovascular disease and other chronic conditions [24].

While several studies in the United States and other countries have examined the prevalence and correlates of PIM use among aged populations [23, 25-32], to the best of our knowledge, few studies have specifically examined the older African-American community [19]. The main objective of this study is to examine PIM use among noninstitutionalized hypertensive older African-American adults, using the revised Beers' criteria (2015), to identify those individuals that may be disproportionately affected by inappropriate drug use to be targeted for appropriate interventions to reduce the use of PIMs. Furthermore, this study examines potential correlations between PIM use and the number and type of chronic conditions. In addition, we present five cases in order to gain insight into PIM use among our sample. These case studies provide a variety of actual scenarios that may help providers to reexamine PIM issues from their perspectives and then synthesize a solution in their own practice.

\section{Methods}

This cross-sectional observational study is comprised of a convenience sample of 193 non-institutionalized African-American adults, aged 65 years and older, with a clinical diagnosis of hypertension.

\section{Participants and setting}

Participants were recruited from several predominantly African-American senior centers and housing units located in underserved areas of South Los Angeles. This study is part of a larger effort to examine medication use among a sample of 342 African Americans aged 55 years and older. However, the current study used only participants that were 65 years of age or older (193) from the study sample to examine the use of PIMs. Only four potential subjects refused to participate in our study. No participants were selected that were residing in skilled nursing facilities. Potential participants were excluded if they were enrolled in other clinical trials. In addition, using a standard screening tool, potential participants with cognitive deficits were excluded from the study. This investigation was approved by the Charles R. Drew University of Medicine and Science Institutional Review Board. A written informed consent was collected from all participants. The study used structured, face-to-face survey interviews. Data used in the study were collected from November 2015 - February 2017.

\section{Measurement}

The survey instrument was a collection of validated instruments from various sources [11, 17, 19, 33-35]. Demographic variables included age, gender, education, living arrangement, and disability status.

Medication use was assessed using the drug inventory method. Participants were asked to bring all over-thecounter and $\mathrm{Rx}$ medications that were taken within 2 weeks prior to the interviews. The interviewer transcribed from the container label the name of the medication, strength of the drug, expiration date, instructions, special warnings, providers' information, etc. The medication assessment of this study employed the methodology established by Sorensen and colleagues [36-38], which was adopted by our research team previously [11, 17, 19, 33-35].

\section{PIM use}

The updated 2015 AGS Beers Criteria was used to identify PIM [20]. In this study PIM was defined as the 
number of medications that must be avoided but were prescribed for an older adult. Based on the 2015 AGS Beers Criteria, calculation of PIM should not count a prescription as a PIM in the presence of certain indications due to specific clinical conditions and criteria [Examples: use of proton-pump inhibitors (PPI) for less than 8 weeks; use of antipsychotics, first- (conventional) and second(atypical) generation for treatment of schizophrenia, bipolar disorder, or short-term use as antiemetic during chemotherapy; use of non-cyclooxygenase-NSAIDs, oral for young-old ( $<75$ years) for short duration; etc.] [20]. In our study, a prescribed medication was considered appropriate (not being counted as a PIM) using the above Beers criterion in 19 PIMs (17 participants).

The AGS 2015 Updated Beers Criteria lists the drug-drug and drug-disease interactions that should be avoided in older adults. We documented the presence of these interactions by referencing this list. PIMs were counted as a total number and an adjusted number, the latter indicating a likely elimination of a medication as a PIM if a medical exception was met.

\section{Chronic conditions}

Participants were asked to report on diagnoses only if a physician had confirmed them previously. We collected information about 13 conditions: diabetes, hypertension, thyroid disorder, cardiac disease, cancer, asthma, osteoarthritis, rheumatoid arthritis, chronic obstructive pulmonary disease, intestinal disease, depression, and hypercholesterolemia. We also used an alternative method based on the labels of medication containers to identify participants' chronic conditions. We assigned a condition to a participant if the therapeutic purpose of the medications used was clearly linked to the presence of a chronic condition. This method (examination of the medication containers) leads to an additional 25 conditions. However, a vast majority of these 25 medical conditions was not frequently diagnosed, including lupus, hepatitis, vertigo, cachexia, herpes, edema, seizures etc. Relying on self-report or administrative data alone in documenting chronic conditions underestimates the prevalence of chronic conditions, which results in biased estimates of multi-morbidity [39].

\section{Sample size and statistical analysis}

Both descriptive and inferential statistics were used to document prevalence and correlates of PIM use among our sample. Pearson correlation coefficients, chi-squared tests, and the binary logistic regression techniques were used to examine the correlation between the PIM use and 1) number of medication use; 2) number of chronic conditions; and 3) type of chronic conditions. Examining correlation between several types of chronic conditions and
PIM, the Bonferroni correction was used to counteract the problem of inflated type I errors. All statistical analyses were performed with the Statistical Package for Social Sciences (SPSS) version 22. Based on previous studies, we expected at least $30 \%$ of study participants will be using at least one PIM [19, 23]. Therefore the sample size of 193 subjects is sufficient to determine the extent of PIM use among older African American adults.

\section{Results}

Table 1 reports the demographic characteristics and health status of our sample. There were 193 study participants, with an age range from 65 to 96 years (M 75.2 \pm 7 ). Approximately $48 \%$ of the participants were 75 years of age or older and $67 \%$ of the participants were women. The number of reported chronic illnesses ranged from one to 17 , with the average being eight $(7.8 \pm 3.2)$. One out of four participants had at least 10 chronic conditions. Participants were taking an average of $7.3(\mathrm{SD}=3.60)$ prescription drugs (range: 1-24). Thirty percent of participants were using at least nine medications, whereas $27 \%$ and $43 \%$ of participants were taking five to eight and one to four prescription medications, respectively (Table 1). In addition, our data shows that nearly $21 \%, 36 \%, 60 \%, 65 \%$ of participants were diagnosed with depression, diabetes mellitus, hyperlipidemia, and chronic pain, respectively.

Our data indicates that inappropriate drug use occurred in 46\% (99) of participants. In addition, 26\% (55) $13 \%$ (25) and $8 \%(19)$ of participants were taking one, two or at least three inappropriate medications, respectively. While the average number of PIMs taken was 0.97 drugs, the range was from one to seven medications. A total of 188 PIMs were used by ninety-nine individuals. Almost 23\% (43 out of 188 PIMs) were due to drugs with potential drug-drug interactions. The most common PIM was the use of proton pump inhibitors (PPI) and greater than two or more Central Nervous System (CNS) active agents, occurring at $46 \%$ and $18 \%$, respectively. Nearly $56 \%$ (105 out of 188) of PIMs potentially increased the risk of falls and fall-associated bone fractures.

The use of PIMs was significantly higher among participants who were taking a higher number of medications $(r=0.51 ; p<.0001)$. Participants who were taking at least six medications were 3.6 times $(\mathrm{OR}=3.6$; $\mathrm{CI}$ : $1.91-6.7 ; p<0.001$ ) more likely to also be receiving inappropriate medications. Similarly, the use of PIMs was significantly higher among participants who reported a higher number of chronic conditions $(r=0.46 ; p<0.0001)$. Participants who were diagnosed with at least six chronic conditions were 2.7 times $(\mathrm{OR}=2.73$; CI: $1.40-5.4$; $p<0.001)$ more likely to be receiving inappropriate medications. In addition, three chronic medical conditions showed a statistically significant independent correlation 
Table 1 Demographic characteristics and health status of sample $(N=193)$

\begin{tabular}{|c|c|}
\hline Demographic and health status & $N(\%)$ \\
\hline \multicolumn{2}{|l|}{ Age } \\
\hline $65-74$ years & $100(52)$ \\
\hline$\geq 75$ years & $93(48)$ \\
\hline \multicolumn{2}{|l|}{ Gender } \\
\hline Male & $63(33)$ \\
\hline Female & $130(67)$ \\
\hline \multicolumn{2}{|l|}{ Education } \\
\hline No high school diploma & $48(25)$ \\
\hline High school diploma & $68(35)$ \\
\hline Some college or more & $77(40)$ \\
\hline \multicolumn{2}{|l|}{ Living Arrangement } \\
\hline Living alone & $150(78)$ \\
\hline Living with someone & $42(22)$ \\
\hline \multicolumn{2}{|l|}{ Disability Status } \\
\hline Yes & $89(44)$ \\
\hline No & $104(54)$ \\
\hline \multicolumn{2}{|l|}{ Diabetes } \\
\hline Yes & $35(18)$ \\
\hline No & $158(82)$ \\
\hline \multicolumn{2}{|l|}{ Hyperlipidemia } \\
\hline Yes & $115(60)$ \\
\hline No & $78(40)$ \\
\hline \multicolumn{2}{|l|}{ Chronic Pain } \\
\hline Yes & $125(65)$ \\
\hline No & $68(35)$ \\
\hline \multicolumn{2}{|l|}{ Depression } \\
\hline Yes & $41(21)$ \\
\hline No & $152(79)$ \\
\hline \multicolumn{2}{|l|}{ Number of Prescribed Medications } \\
\hline $0-4$ & $52(27)$ \\
\hline $5-8$ & $84(43)$ \\
\hline $9-24$ & $57(30)$ \\
\hline \multicolumn{2}{|l|}{ Number of Chronic Conditions } \\
\hline $1-5$ & $55(29)$ \\
\hline $6-10$ & $93(48)$ \\
\hline $11-17$ & $45(23)$ \\
\hline
\end{tabular}

with PIM use. Participants who were diagnosed with chronic pain $(\mathrm{OR}=2.4 ; \mathrm{CI}: 1.3-4.5 ; P<.005)$, depression $(\mathrm{OR}=2.8$; CI: $1.4-5.8 ; P<.005)$, and gastroesophageal reflux disease $(\mathrm{OR}=2.9$; $\mathrm{CI}$ : $1.6-5.3 ; P<.0001)$ were 2.4 , 2.8 and 2.9 times, respectively, more likely to use PIMs than their counterparts without these chronic conditions.

\section{Case studies}

Case 47

The participant is in her 70s with a medical history of osteoporosis, recent fall (12 months ago), depression, sleep disorder, and chronic pain. She has a total of 12 self-reported medical conditions and is taking a total of five potentially inappropriate medications (PIMs). At the time of the survey, the participant was taking a PPI for 12 months. PPI use longer than 8 weeks is considered a PIM as it increases the risk of developing Clostridium difficile infection and bone loss and fractures. She was also taking nortriptyline, a tricyclic anti-depressant with strong anti-cholinergic properties, and hydrocodone-acetaminophen. These two drugs separately and together have the potential of a $>2$ CNS active agent drug-drug interaction, increasing the risk of falls and/or fractures. Lastly, the participant is taking meloxicam, a non-steroidal anti-inflammatory drug (NSAID), which in patients older than 74 years of age, poses considerable risk for peptic ulcer disease and/or development of gastrointestinal bleeding.

\section{Case 102}

The participant is in her 70's with a medical history significant for Parkinson's disease, dependent activities of daily living (ADLs), depression and heart problems with a pacemaker. She has a total of 12 self-reported medical conditions, one-third of which are associated with PIMs that pose a significant risk of morbidity. At the time of the survey, the participant was taking a PPI for 2 weeks, although the medication had been prescribed for 12 months. She was also taking hydrocodone-acetaminophen and risperidone, which together has the potential of a $>2$ CNS active agent drug-drug interaction increasing the risk of falls and/or fractures. In the case of this participant, this would hold true as the participant has both dependent ADLs and Parkinson's disease. Of particular significance is the use of the anti-psychotic risperidone in this participant with her concurrent diagnoses of Parkinson's disease. All antipsychotics, with the exception of aripiprazole, quetiapine, and clozapine, are believed to carry the risk of the precipitation and worsening of Parkinson's symptoms.

\section{Case 229}

The participant is in her 80s with a medical history significant for hypertension, sleep disorder and chronic pain. She has a total of eight self-reported medical conditions and a total of six PIMs including three separate drug-drug interactions. The participant is taking triamterene and lisinopril which together pose a risk for drug-drug interactions due to an increased risk of hyperkalemia. The participant is also taking temazapam, which by itself and together with nortriptyline and hydrocodone poses two separate $>2$ CNS drug interactions and increases the risk of cognitive impairment, delirium, falls, fractures, and 
motor-vehicle accidents. Nortriptyline by itself and together with hydrocodone and temazapam has the potential of two separate $>2$ CNS drug-drug interactions and present a PIM with risks as described above. The participant has a significant risk for morbidity for taking $>3$ CNS active agents.

\section{Case 249}

The participant is in his seventies with a medical history significant for dependent ADLs, heart problems, chronic pain and a sleep disorder. He has a total of 13 self-reported medical conditions and is taking a total of 13 medications, six of which are PIMs including three sets of drug-drug interactions. Tramadol and codeine are both opiates and are identified as PIMs as individual drugs in patients with a history or risk of falls or fracture, as is the case in this patient with dependent ADLs. Together these drugs also pose a $>2$ CNS active drug-drug interaction. The participant is also taking a corticosteroid and NSAIDs, which together can cause a drug-drug interaction and increase the risk of peptic ulcer disease and/or gastrointestinal bleeding. Lastly, the participant is taking diphenhydramine, which by itself is a PIM in patients with a history or risks of falls and/or fractures. Diphenhydramine together with solifenacin is a risk for drug-drug interaction as both drugs are strong anticholinergics, increasing the risk of cognitive decline.

\section{Case 288}

The participant is in her 80 s with a medical history of dependent ADLs, rheumatoid arthritis, thyroid disease, and breast cancer remission. She also has a total of 16 self-reported medical conditions, is taking a total of 16 medications, seven of which are PIMs including three sets of drug-drug interactions. The participant is taking lorazepam, oxycodone, and morphine, which by themselves are PIM in patients with a history or risk of falls and/or fracture, as is the case of this participant who has dependent ADLs. Together these CNS active agents create three different sets of $>2$ CNS active agent drug-drug interactions. Lastly, the participant was taking a PPI for 7 months, which increases the risk of clostridium difficile, fractures, and falls.

\section{Discussion}

Use of medication that may cause more harm than benefit is considered potentially inappropriate when safer pharmacological or non-pharmacological alternatives exist [40]. Older African-American adults are a particularly vulnerable population as they suffer from a higher number of chronic conditions than their white counterparts. Our data show that $41 \%$ of older hypertensive African Americans were taking at least eight medications. In addition, one out of four participants reported at least
10 chronic conditions. Yet we documented that one out of two participants are taking at least one inappropriate medication. Similar to this study, a recent study conducted among a sample of 400 older underserved African-American adults reported a high rate of PIM use [19]. The rate of PIM use in our study is substantially higher than previously reported PIM use among older adults. The 2006-2010 Medical Expenditure Panel Survey (MEPS), shows that one-third (32.8\%) of older African-American adults used a PIM [24]. The higher rate of PIM use in our sample may reflect the fact that our sample has been recruited from the Service Planning Area 6 (SPA 6) of Los Angeles County, one of the most underserved minority communities in the US. We specifically selected SPA 6 because nearly half of older adults living in SPA 6 are African American (49\%). Home to more than one million residents, SPA 6 has disproportionately greater health disparities than the rest of Los Angeles County [41]. A good example is the age-adjusted coronary heart disease death rate which is significantly higher for SPA 6 (147.5 per 100,000 population) than the Nation (102.6) and the rest of Los Angeles County (116.7). Another example is the aged-adjusted diabetes death rate which is 37.6, 21.9, and 21.2 per 100,000 population for the SPA 6, Los Angeles County and the Nation, respectively [41].

Both quantitative analysis and the cases reported here show that chronic pain is one of the important common denominators of PIM use. Fifty-four percent of our study population who were diagnosed with chronic pain consume at least one PIM. Indeed, it is not surprising that suffering from chronic pain leads to PIM use. Previous studies have also shown that inappropriate pain medications are frequently prescribed for older adults [42]. However, empirical evidence suggests that older African Americans have a higher risk for severe pain compared with non-Hispanic whites [43]. Yet severe mismanagement of pain in underserved older African Americans, particularly those with comorbidity, multiple providers, and limited access to health care has been documented [19]. A recent study shows that one in four older African American were taking NSAIDs, which can cause serious side effects in older adults with multiple chronic conditions [19]. The use of pain medication was associated with drug-drug interactions, drug duplication, and PIM use [19]. These results support the need for clinicians to be aware of PIM use by older adults, recognize associated medication-related adverse events, and avoid prescribing age-inappropriate medications to vulnerable older adult patients [42].

Another commonly prescribed PIM in our study was taken by participants who were diagnosed with the gastroesophageal reflux disease (GERD). A recent study examining the PIM use among older patients with 
cardiovascular disease also listed the unnecessary use of PPIs common among older adults [44]. It is important that providers carefully consider the use of PPIs in older adults and monitor their continued use to prevent the drug-drug interactions and side effects, including risk of Clostridium difficile infection, bone loss, and fractures [45].

In addition, another common denominator for PIM use, both in our case studies and in the quantitative analysis, was diagnoses of depression among our older AfricanAmerican adults. Given that several psychotropic drugs are included in Beers' list, it was not surprising to find that the presence of depressive symptoms was associated with potentially inappropriate medication use. Other studies have confirmed this association [46]. It has been empirically documented that use of anti-cholinergic medications that are listed as PIMs leads to cognitive declines and dementia among older adults [47]. Therefore, it is important that physicians avoid prescribing anti-cholinergic medication listed as PIMs, particularly for old-old adults [47]. In addition, the standard care for dementia should include careful medication review and management to avoid PIM use in this vulnerable population [48].

Another overarching theme that emerged from our case reports is the history of falls and use of PIMs that substantially increases the risk of falls among our participants. Our data shows that $56 \%$ of PIMs used by our participants potentially increased the risk of falls and fall-associated bone fractures. Several studies documented that PIM use has been associated with an increased risk of falls and hip fractures [21]. There are mixed findings in the literature in regards to the racial differences on falls among older adults. Many studies found that older non-Hispanic Whites were more likely to fall than older African Americans [49-51], yet several studies revealed no racial differences or excessive falls rates among African-American older adults compared to their White counterparts [5255]. However, African Americans have a greater fall-risk profile when compared to non-Hispanic Whites. Older African Americans' higher fall-risk scores are attributed to their physical functioning and medication use [56] and poorer self-rated health and multiple comorbidities [57]. The 2014 Behavioral Risk Factor Surveillance System survey shows that regardless of ethnic background, the rate of fall-related injuries is significantly higher in the older adults with poor health (480 per 1000) than their counterparts with excellent health (69 per 1000) [58]. Managing at least one chronic disease increases the risk of falling by 32\% [59]. The most recent report from the Center for Medicare and Medicaid Services (CMS) Chronic Condition Data Warehouse shows a higher prevalence of major chronic conditions among African-American older adults compared to their non-Hispanic White counterparts. African-American older adults experience higher rates of hypertension ( $68.4 \%$ vs 57.7$)$, diabetes ( $39.8 \%$ vs. 24.7$)$, chronic kidney disease (26.7 vs. 18.2), heart failure (17.9\% vs. $14.3 \%)$, Alzheimer's disease/dementia (14.2\% vs. $11.3 \%)$ stroke $(5.7 \%$ vs. 4.2$)$ and cancer $(10.1 \%$ vs. $9.1 \%)$. Therefore, it is imperative that providers who are prescribing medications to African-American older adults with multiple chronic conditions, be cognizant of the vulnerability of their patients and avoid prescribing the PIMs that increase the risk of falls.

\section{Limitations of the study}

The research team did not have access to the participants' medical records to record the medications that were prescribed for participants. Medication-related information was collected directly from drug containers. Second, the study used a convenience sample, which limits the generalizability of our findings. Finally, we used a cross-sectional study design, which allowed us to collect data at only a single point in time. Nevertheless, this study provides vital information about a population (underserved African-American older adults) that has not been carefully studied to this point.

\section{Conclusions}

The revised AGS Beers criteria provides valuable tools to guide prescribing in older adults. All clinicians who provide medical care for older adults should be familiar with this tool. However, it is important to note that reducing PIMs is only one component of improving quality of care for older adults [60]. Relying only on Beers criteria obscures the detection of important drug-related problems such as drug use without an indication, untreated conditions, or poor adherence [61]. PIM, polypharmacy, and nonadherence to medications are all interconnected, and these factors are linked to effectiveness of medications and health outcomes among older adults $[11,19,62]$. However, no intervention trials have focused on these medication-related challenges together to improve adherence to medications among AfricanAmerican older adults [63]. Therefore, the first step in reducing medication-related challenges and improving the effectiveness and management of medications among older adults, particularly older African-American adults, is to conduct a comprehensive assessment of their medications [64].

The likely reason for high levels of polypharmacy, PIMs, and drug interactions is that patients suffer from multiple chronic conditions. But it may not be possible or necessary to treat all chronic conditions. Therefore, the goals of care should be explicitly reviewed with the patient (or, if the patient has limited capacity for decision making, with the patient's caretaker) in order to determine which of the many chronic conditions has the greatest impact on the life goals and/or functional priorities of the patient. Those drugs that have a limited 
impact on the patient's functional priorities and that may cause harmful drug-drug interactions can be reduced or eliminated, while the remaining medications can focus on the most important functional priorities of the patient.

A recent interventional study used electronic alerts at the point of computerized order-entry to reduce PIM prescribing among a large sample of older veteran adults. The study showed a modest reduction in the rate of the top 10 most common newly-prescribed PIMs (from 9.0 to 8.3\%; $p=0.016$ ). This intervention was only able to modify the prescribing behaviors of neurologists and detected no positive impact on prescribing of other provider specialists [65]. This is another indication that multidimensional and multicomponent interventions are needed to focus on the relationship between comorbidities and medication-related challenges among African-American older adults $[66,67]$.

The four case reports given above clearly show that there is additional need for multidisciplinary interventions to reduce medication-related challenges among older African-American adults with comorbidities, particularly those who suffer from pain. Safe and appropriate prescribing is a complex process, involving issues of over-prescription, under-prescription, and inappropriate prescription [68]. Without close and continuous collaboration between providers and patients with a coherent multi-pronged strategy, de-prescribing, as part of the solution to address over-prescribing and inappropriate prescribing, is almost impossible.

\begin{abstract}
Abbreviations
ADL: Activities of daily living; AGS: American Geriatrics Society; Cl: Confidence intervals; CMS: Center for Medicare and Medicaid Services; CNS: Central nervous system; GERD: Gastroesophageal reflux disease; HTN: Hypertension; MEPS: Medical expenditure panel survey; NSAID: Non-steroidal anti-inflammatory drug; OR: Odds ratio; PIM: Potentially inappropriate medication; PPI: Proton pump inhibitors; Rx: Prescription medication; SPA 6: Service planning area 6;

SPSS: Statistical package for social sciences
\end{abstract}

\section{Acknowledgements}

We thank all participants who patiently participated in lengthy face-to-face interviews and allowed us to document all medications that they use. Additionally, we sincerely acknowledge the valuable suggestions and comments from Dr. Thomas Yoshikawa who carefully reviewed this manuscript.

\section{Funding}

CMS: "1l0CMS331364-01" and NIMHD: "U54MD007598" and "R25 MD007610." The Funding agencies had no role in the design of the study and collection, analysis, interpretation of data, or in writing the manuscript.

\section{Availability of data and materials}

The datasets analyzed during the current study are not publicly available. We used only a subset of data (baseline) from an on-going interventional study. Within the next 12 months, data collection will be completed and the data will be available from the corresponding author on reasonable request.

\section{Authors' contributions}

All authors have contributed significantly and they all are in agreement with the content of the manuscript. MB was the primary investigator, leading the study, involved in conception and design, data analysis and writing of the manuscript. JLS contributed to the acquisition of participants, data collection, and interpretation of data. EOK was involved in interpretation of data and drafting the manuscript.

\section{Ethics approval and consent to participate}

The Charles R. Drew University of Medicine and Science Institutional Review Board approved this study (IRB \#14-12-2450). Written informed consent was obtained from all participants. This study did not examine medical files of any individuals who participated in this study. All data collected from 193 participants were self-reports. In addition, participants' medication was documented from medication containers. However, participants signed an individual consent permitting the data collected from their survey to be published without compromising their identity.

\section{Consent for publication}

The written informed consent for this study was completed according to the established roles and guidelines that were approved by the Institutional Review Board prior to study initiation. Written consent was obtained from all participants. In addition, written and signed consent was obtained from participants described in case studies for publicizing their individual information.

\section{Competing interests}

The authors declare that they have no competing interests.

\section{Publisher's Note}

Springer Nature remains neutral with regard to jurisdictional claims in published maps and institutional affiliations.

Received: 20 December 2017 Accepted: 23 September 2018

Published online: 05 October 2018

\section{References}

1. Howard G, Safford MM, Moy CS, et al. Racial differences in the incidence of cardiovascular risk factors in older black and white adults. J Am Geriatr Soc. 2017;65(1):83-90.

2. Oh J-Y, Allison MA, Barrett-Connor E. Different impacts of hypertension and diabetes mellitus on all-cause and cardiovascular mortality in communitydwelling older adults: the rancho Bernardo study. J Hypertens. 2017;35(1):55-62.

3. Franklin SS, Thijs L, Li Y, et al. Masked hypertension in diabetes mellitus: treatment implications for clinical practice. Hypertension. 2013;61:964-71.

4. Center for Medicare and Medicaid Services. Prevalence state level: all beneficiaries by race/ethnicity and age, 2007-2015: multiple chronic conditions prevalence state table: black or African American fee-for-service beneficiaries by age, 2015. 2016. https://www.cms.gov/Research-StatisticsData-and-Systems/Statistics-Trends-and-Reports/Chronic-Conditions/MCC_ Main.html. Accessed July 2017.

5. Center for Medicare and Medicaid Services. Chronic conditions prevalence state table: black or African American fee-for-service beneficiaries by age, 2015. 2016. https://www.cms.gov/Research-Statistics-Data-and-Systems/StatisticsTrends-and-Reports/Chronic-Conditions/MCC_Main.html. Accessed July 2017.

6. Charlesworth CJ, Smit E, Lee DS, Alramadhan F, Odden MC. Polypharmacy among adults aged 65 years and older in the United States: 1988-2010. J Gerontol A Biol Sci Med Sci. 2015;70:989-95.

7. Krousel-Wood MA, Muntner P, Islam T, Morisky DE, Webber LS. Barriers to and determinants of medication adherence in hypertension management: perspective of the cohort study of medication adherence among older adults. Med Clin North Am. 2009;93(3):753-69.

8. Young JH, $\mathrm{Ng} \mathrm{D}$, Ibe C, et al. Access to care, treatment ambivalence, medication nonadherence, and long-term mortality among severely hypertensive African Americans: a prospective cohort study. J Clin Hypertens (Greenwich). 2015;17(8):614-21.

9. Zolnierek KB, Dimatteo MR. Physician communication and patient adherence to treatment: a meta-analysis. Med Care. 2009;47(8):826-34

10. Ayalon L, Arean PA, Alvidrez J. Adherence to antidepressant medications in black and Latino elderly patients. Am J Geriatr Psychiatr. 2005;13(7):572-80.

11. Bazargan M, Smith J, Yazdanshenas H, Movassaghi M, Martins M, Orum G. Non-adherence to medication regimens among older African-American adults. BMC Geriatr. 2017; In Print.

12. Braverman J, Dedier J. Predictors of medication adherence for African American patients diagnosed with hypertension. Ethn Dis. 2009;19(4):396-400.

13. Gerber BS, Cho Yl, Arozullah AM, Lee SY. Racial differences in medication adherence: a cross-sectional study of Medicare enrollees. Am J Geriatr Pharmacother. 2010;8(2):136-45. 
14. Zhang Y, Baik SH. Race/ethnicity, disability, and medication adherence among medicare beneficiaries with heart failure. J Gen Intern Med. 2014; 29(4):602-7

15. Davis AM, Taitel MS, Jiang J, et al. A National Assessment of medication adherence to statins by the racial composition of neighborhoods. J Racial Ethn Health Disparities. 2017:4(3):462-71.

16. Lewey J, Shrank WH, Bowry AD, Kilabuk E, Brennan TA, Choudhry NK. Gender and racial disparities in adherence to statin therapy: a meta-analysis. Am Heart J. 2013;165(5):665-78 678 e661.

17. Bazargan M, Smith J, Movassaghi M, et al. Polypharmacy among underserved older African American adults. J Aging Res. 2017;2017. Article ID 6026358, 8 pages. https://doi.org/10.1155/2017/6026358.

18. Espino DV, Bazaldua OV, Palmer RF, et al. Suboptimal medication use and mortality in an older adult community-based cohort: results from the Hispanic EPESE study. J Gerontol Ser A Biol Med Sci. 2006:61(2):170-5.

19. Bazargan M, Yazdanshenas H, Han S, Orum G. Inappropriate medication use among underserved elderly African Americans. J Aging Health. 2016;28(1):118-38.

20. Radcliff S, Yue J, Rocco G, et al. American Geriatrics Society 2015 updated beers criteria for potentially inappropriate medication use in older adults. Am Geriatr Soc. 2015;63(11):2227-46.

21. Naples JG, Hanlon JT, Ruby CM, Greenspan SL. Inappropriate Medications and Risk of Falls in Older Adults. In: Huang A, Mallet L, editors. MedicationRelated Falls in Older People. Adis, Cham. 2016.

22. Muhlack DC, Hoppe LK, Weberpals J, Brenner H, Schöttker B. The Association of Potentially Inappropriate Medication at older age with cardiovascular events and overall mortality: a systematic review and metaanalysis of cohort studies. J Am Med Dir Assoc. 2017;18(3):211-20.

23. Opondo D, Eslami S, Visscher $\mathrm{S}$, et al. Inappropriateness of medication prescriptions to elderly patients in the primary care setting: a systematic review. PLoS One. 2012;7(8):e43617.

24. Miller GE, Sarpong EM, Davidoff AJ, Yang EY, Brandt NJ, Fick DM. Determinants of potentially inappropriate medication use among community-dwelling older adults. Health Serv Res. 2017;52(4):1534-49.

25. Skaar DD, O'Connor HL. Use of the beers criteria to identify potentially inappropriate drug use by community-dwelling older dental patients. Oral Surg Oral Med Oral Pathol Oral Radiol. 2012;113(6):714-21.

26. Singh J. Evaluation of the appropriateness of prescribing in geriatric patients using Beers' criteria and Phadke's criteria and comparison thereof by Rima Shah and colleagues. J Pharmacol Pharmacother. 2012;3(1):81-2.

27. Vishwas HN, Harugeri A, Parthasarathi G, Ramesh M. Potentially inappropriate medication use in Indian elderly: comparison of Beers' criteria and screening tool of older Persons' potentially inappropriate prescriptions. Geriatr Gerontol Int. 2012;12(3):506-14.

28. Monroe T, Carter M, Parish A. A case study using the beers list criteria to compare prescribing by family practitioners and geriatric specialists in a rural nursing home. Geriatr Nurs. 2011;32(5):350-6.

29. Locatelli J, Lira AR, Torraga LK, Paes AT. Inappropriate medications using the beers criteria in Brazilian hospitalized elderly patients. Consult Pharm. 2010; 25(1):36-40.

30. Gallagher PF, Barry PJ, Ryan C, Hartigan I, O'Mahony D. Inappropriate prescribing in an acutely ill population of elderly patients as determined by Beers' criteria. Age Ageing. 2008;37(1):96-101.

31. Niwata S, Yamada Y, Ikegami N. Prevalence of inappropriate medication using beers criteria in Japanese long-term care facilities. BMC Geriatr. 2006;6:1.

32. van der Hooft CS, Jong GW, Dieleman JP, et al. Inappropriate drug prescribing in older adults: the updated 2002 beers criteria--a populationbased cohort study. Br J Clin Pharmacol. 2005;60(2):137-44.

33. Yazdanshenas H, Bazargan M, Orum G, Loni L, Mahabadi N, Husaini B. Prescribing patterns in the treatment of hypertension among underserved African American elderly. Ethn Dis. 2014:24(4):431-7.

34. Yazdanshenas H, Bazargan M, Smith J, Martins D, Motahari H, Orum G. Pain treatment of underserved older African Americans. J Am Geriatr Soc. 2016; 64(10):2116-21.

35. Bazargan M, Yazdanshenas $\mathrm{H}$, Gordon D, Orum G. Pain in communitydwelling elderly African Americans. J Aging Health. 2016;28(3):403-25.

36. Sorensen L, Stokes JA, Purdie DM, Woodward M, Roberts MS. Medication management at home: medication risk factor prevalence and interrelationships. J Clin Pharm Ther. 2006:31(5):485-91.

37. Sorensen L, Stokes JA, Purdie DM, Woodward M, Roberts MS. Medication management at home: medication-related risk factors associated with poor health outcomes. Age Ageing. 2005;34(6):626-32.
38. Sorensen L, Stokes JA, Purdie DM, Woodward M, Elliott R, Roberts MS. Medication reviews in the community: results of a randomized, controlled effectiveness trial.[erratum appears in Br J Clin Pharmacol. 2005 mar;59(3): 376]. Br J Clin Pharmacol. 2004;58(6):648-64.

39. Fortin M, Haggerty J, Sanche S, Almirall J. Self-reported versus health administrative data: implications for assessing chronic illness burden in populations. A cross-sectional study. CMAJ Open. 2017;5(3):E729-33.

40. Tannenbaum C, Farrell B, Shaw J, et al. An ecological approach to reducing potentially inappropriate medication use: Canadian Deprescribing network-erratum. Can J Aging/La Revue canadienne du vieillissement. 2017:36(2):268-71

41. Los Angeles County Department of Public Health, Office of Health Assessment and Epidemilogy. Key Indicators of Health by Service Planning Area. January 2017. www.publichealth.lacounty.gove/ha. Accessed 272018.

42. Skaar DD, O'Connor $\mathrm{H}$. Using the beers criteria to identify potentially inappropriate medication use by older adult dental patients. J Am Dent Assoc. 2017:148(5):298-307.

43. Reyes-Gibby CC, Aday LA, Todd KH, Cleeland CS, Anderson KO. Pain in aging community-dwelling adults in the United States: non-Hispanic whites, non-Hispanic blacks, and Hispanics. J Pain. 2007:8(1):75-84.

44. Sheikh-Taha M, Dimassi H. Potentially inappropriate home medications among older patients with cardiovascular disease admitted to a cardiology service in USA. BMC Cardiovasc Disord. 2017;17(1):189.

45. Corleto VD, Festa S, Di Giulio E, Annibale B. Proton pump inhibitor therapy and potential long-term harm. Curr Opin Endocrinol Diabetes Obes. 2014; 21(1):3-8

46. Lechevallier-Michel N, Gautier-Bertrand M, Alperovitch A, et al. Frequency and risk factors of potentially inappropriate medication use in a community-dwelling elderly population: results from the $3 \mathrm{C}$ study. Eur J Clin Pharmacol. 2005:60(11):813-9.

47. Heser K, Luck T, Rohr S, et al. Potentially inappropriate medication: association between the use of antidepressant drugs and the subsequent risk for dementia. J Affect Disord. 2018;226:28-35.

48. Wucherer D, Eichler T, Hertel J, et al. Potentially inappropriate medication in community-dwelling primary care patients who were screened positive for dementia. J Alzheimers Dis. 2017:55(2):691-701.

49. de Rekeneire N, Visser M, Peila R, et al. Is a fall just a fall: correlates of falling in healthy older persons. The health, aging and body composition study. J Am Geriatr Soc. 2003;51(6):841-6.

50. Hanlon JT, Landerman LR, Fillenbaum GG, Studenski S. Falls in African American and white community-dwelling elderly residents. J Gerontol A Biol Sci Med Sci. 2002;57(7):M473-8.

51. Karter AJ, Laiteerapong $\mathrm{N}$, Chin $\mathrm{MH}$, et al. Ethnic differences in geriatric conditions and diabetes complications among older, insured adults with diabetes: the diabetes and aging study. J Aging Health. 2015;27(5):894-918.

52. Faulkner KA, Cauley JA, Zmuda JM, et al. Ethnic differences in the frequency and circumstances of falling in older community-dwelling women. J Am Geriatr Soc. 2005;53(10):1774-9.

53. Means KM, O'Sullivan PS, Rodell DE. Balance, mobility, and falls among elderly African American women. Am J Phys Med Rehabil. 2000;79(1):30-9.

54. Quandt SA, Stafford JM, Bell RA, Smith SL, Snively BM, Arcury TA. Predictors of falls in a multiethnic population of older rural adults with diabetes. J Gerontol A Biol Sci Med Sci. 2006:61(4):394-8.

55. Geng Y, Lo JC, Brickner L, Gordon NP. Racial-ethnic differences in fall prevalence among older women: a cross-sectional survey study. BMC Geriatr. 2017;17(1):65.

56. Ellis R, Kosma M, Fabre JM, Moore DS, Wood RH. Proximal determinants of falls risk among independent-living older adults. Res Aging. 2012;35(4):420-36.

57. Nicklett EJ, Taylor RJ, Rostant O, Johnson KE, Evans L. Biopsychosocial predictors of fall events among older African Americans. Res Aging. 2017:39(4):501-25.

58. Bergen $\mathrm{G}$, Stevens MR, Burns ER. Falls and fall injuries among adults aged >/=65 years - United States, 2014. MMWR Morb Mortal Wkly Rep. 2016; 65(37):993-8.

59. Lawlor DA, Patel R, Ebrahim S. Association between falls in elderly women and chronic diseases and drug use: cross sectional study. BMJ (Clin Res Ed). 2003;327(7417):712-7.

60. Barenholtz Levy H, Marcus E-L. Potentially inappropriate medications in older adults: why the revised criteria matter. Ann Pharmacother. 2016;50(7):599-603.

61. Verdoorn S, Kwint H-F, Faber A, Gussekloo J, Bouvy ML. Majority of drugrelated problems identified during medication review are not associated with STOPP/START criteria. Eur J Clin Pharmacol. 2015;71(10):1255-62. 
62. Gellad WF, Grenard IL, Marcum ZA. A systematic review of barriers to medication adherence in the elderly: looking beyond cost and regimen complexity. Am J Geriatr Pharmacother. 2011;9(1):11-23.

63. Hu D, Juarez DT, Yeboah M, Castillo TP. Interventions to increase medication adherence in African-American and Latino populations: a literature review. Hawaii J Med Public Health. 2014;73(1):11-8.

64. Bazargan M, Smith J, Yazdanshenas H, Movassaghi M, Martins D, Orum G. Non-adherence to medication regimens among older African-American adults. BMC Geriatr. 2017;17(1):163.

65. Vanderman AJ, Moss JM, Bryan WE III, Sloane R, Jackson GL, Hastings SN. Evaluating the impact of medication safety alerts on prescribing of potentially inappropriate medications for older veterans in an ambulatory care setting. J Pharm Pract. 2017;30(1):82-8.

66. Peek ME, Cargill A, Huang ES. Diabetes health disparities: a systematic review of health care interventions. Med Care Res Rev. 2007:64(5 Suppl):101S-56S.

67. Ruppar TM, Dunbar-Jacob JM, Mehr DR, Lewis L, Conn VS. Medication adherence interventions among hypertensive black adults: a systematic review and meta-analysis. J Hypertens. 2017;35(6):1145-54

68. Spinewine A, Schmader KE, Barber N, et al. Appropriate prescribing in elderly people: how well can it be measured and optimised? Lancet. 2007; 370(9582):173-84.

Ready to submit your research? Choose BMC and benefit from:

- fast, convenient online submission

- thorough peer review by experienced researchers in your field

- rapid publication on acceptance

- support for research data, including large and complex data types

- gold Open Access which fosters wider collaboration and increased citations

- maximum visibility for your research: over $100 \mathrm{M}$ website views per year

At BMC, research is always in progress.

Learn more biomedcentral.com/submissions 